\section{Direct Conversion of Aldehydes to Amides, Tetrazoles, and Triazines in Aqueous Media by One-Pot Tandem Reactions}

\author{
J iun-J ie Shie and J im-Min Fang* \\ Department of Chemistry, National Taiwan University, \\ Taipe', Taiwan 106 \\ jmfang@ccms.ntu.edu.tw
}

Received September 6, 2002

\begin{abstract}
A variety of aldehydes reacted with iodine in ammonia water at room temperature to give the nitrile intermediates, which were trapped by addition of hydrogen peroxide, sodium azide, or dicyandiamide to produce their corresponding amides, tetrazoles, and 1,3,5-triazines in modest to high yields. The one-pot tandem reactions were conducted in water media, and the products were obtained simply by extraction or filtration.
\end{abstract}

In comparison with some inflammable and toxic organic solvents, water may serve as a superior solvent that is safe to use in organic reactions. ${ }^{1}$ The low cost of water renders the chemical processes more economical. In many cases, water can be recycled to alleviate the problem of solvent disposal. Furthermore, using water as a solvent may al so have advantages of simple operation and high efficiency in many organic reactions that involve watersoluble substrates and reagents. ${ }^{1}$ For example, we have recently found a direct method for transformation of aldehydes $\mathbf{1}$ to nitriles $\mathbf{2}$ by using iodine in ammonia water (eq 1$)^{2}$ instead of liquid ammonia or ammonia gas saturated in alcohol solvents. This transformation is completed within a short period $(<1 \mathrm{~h})$ at room temperature. A variety of aldehydes, including aromatic, heterocyclic, aliphatic, conjugated, and polyhydroxy aldehydes, have thus been converted to their corresponding nitriles in high yields (83-97\%). This transformation utilizes iodine as an appropriate oxidant and presumably proceeds with an intermediate of $\mathrm{N}$-iodo aldimine $(\mathbf{A}), 3,4 \mathrm{e}$ which eliminates an $\mathrm{HI}$ molecule in ammonia solution to afford the nitrile product. When compared to the previously reported procedures ${ }^{4}$ that use various oxidants and promoters in organic solvents, our method appears to be simple, efficient, and environmentally benign.

Nitrile compounds are viable precursors for preparation of a variety of nitrogen-containing functional com-

(1) (a) Reichardt, C. In Solvents and Solvent Effects in Organic Chemistry; VCH: Weinheim, Germany, 1988. (b) Li, C.J . Chem. Rev. 1993, 93, 2023. (c) Li, C. J . In Organic Reactions in Aqueous Media; Wiley: New York, 1997. (d) Lindström, U. M. Chem. Rev. 2002, 102, 2751.

(2) Talukdar, S.; Hsu, J .-L.; Chou, T.-K.; Fang, J .-M. Tetrahedron Lett. 2001, 42, 1103.

(3) Misono, A.; Osa, T.; Koda, S. Bull. Chem. Soc. J pn. 1967, 40, 2875.

(4) (a) Brackman, W.; Smit, P. J . Recl. Trav. Chim. 1963, 82, 757. (b) Parameswaran, K. N.; Friedman, O. M. Chem. Ind. (London) 1965, 988. (c) Misono, A.; Osa, T.; Koda, S. Bull. Chem. Soc. J pn. 1966, 39, 854. (d) Sato, R.; Itoh, K.; Nishina, H.; Goto, T., Saito, M. Chem. Lett. 1984, 1913. (e) Okimoto, M.; Chiba, T.J . Org. Chem. 1988, 53, 218. (f) Erman, M. B.; Snow, J. W.; Williams, M. J. Tetrahedron Lett. 2000, $41,6749$.

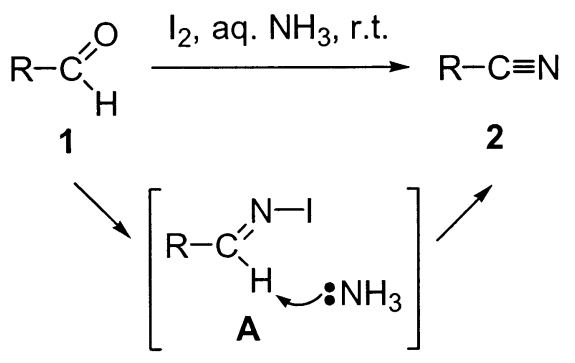

pounds. ${ }^{5}$ It would be desirable that one could start with the readily available aldehydes to carry out tandem reactions, via the intermediacy of nitriles, in aqueous media to furnish other nitrogen-containing functional compounds of biological and material importance. In this paper, we wish to demonstrate that this type of tandem reaction in a one-pot procedure can provide an expedient route to amides 3, triazoles 4, and tetrazines 5 (eqs 2-4). The results are collected in Table 1.

When benzal dehyde ( $5 \mathrm{mmol}$ ) was treated with iodine (5.5 mmol) in ammonia water ( $30 \mathrm{~mL}$ of $28 \%$ solution) and THF $(5 \mathrm{~mL})$ at room temperature for $1 \mathrm{~h}$, the dark solution became colorless as iodine was consumed. A practically pure product of benzonitrile ( $96 \%$ yield) was obtained after charge with aqueous $\mathrm{Na}_{2} \mathrm{~S}_{2} \mathrm{O}_{3}$ and extraction with ether.2 On the other hand, benzamide was produced in $98 \%$ yield if the reaction mixture was charged with aqueous $\mathrm{H}_{2} \mathrm{O}_{2}$ (35\% solution) for $2.5 \mathrm{~h}$. The two-step reaction sequence is mandatory to procure ami de products in high yields. If $\mathrm{H}_{2} \mathrm{O}_{2}$ was added together with $\mathrm{I}_{2}$ to benzaldehyde in ammonia water, only a $35 \%$ yield of benzamide was obtained. The decreased yield was presumably due to a partial consumption of $\mathrm{I}_{2}$ by $\mathrm{H}_{2} \mathrm{O}_{2}{ }^{6}$ The presumed generation of hypoiodic acid might also cause the side oxidations of aldehyde to other unidentified compounds. ${ }^{4 c, f}$ Benzaldehydes bearing either electrondonating or electron-withdrawing substituents (e.g., 4-methoxybenzaldehyde (1b) and 4-nitrobenzaldehdye (1c)) gave the substituted benzamides (e.g., $\mathbf{3 b}$ and $\mathbf{3 c}$ ) in high yields by the similar reaction procedures. It is known that nitrile compounds can be converted to their corresponding amides by heating (e.g., 40-50 ${ }^{\circ} \mathrm{C}$ ) with alkaline hydrogen peroxide in organic solvents (e.g., acetone, ethanol, dioxane, THF , and DMSO). ${ }^{7}$ The hydration of nitrile is initiated by a nucleophilic addition of - $\mathrm{OOH}$ ion to the cyano group, giving an intermediate peroxycarbaximidic acid (B), which is then reduced by $\mathrm{H}_{2} \mathrm{O}_{2}$ (or DMSO) to produce carboxamide along with dioxygen (or dimethyl sulfone). ${ }^{7}$ We have mentioned that $\mathrm{I}^{-}$ion was generated during the reaction of aldehyde with $\mathrm{I}_{2} / \mathrm{aq} \mathrm{NH}_{3}$ to form a nitrile product. Thus, a facilitated degradation of the peroxycarbaximidic acid intermediate,

(5) (a) Mowry, D. T. Chem. Rev. 1948, 42, 250. (b) Friedrich, K.; Wallensfels, K. In The Chemistry of Cyano Group; Rappoport, Z., Ed. Wiley-I nter Science: New York, 1970. (c) North, M. In Comprehensive Organic Functional Group Transformations; Katritzky, A. R., MethConn, O., Rees, C. W., Eds.; Pergamon: 1995; pp 617-618.

(6) Ball, J. M.; Hnatiw, J . B. Can. J . Chem. 2001, 79, 304.

(7) (a) Wiberg, K. B. J. Am. Chem. Soc. 1953, 75, 3961. Sawaki, Y.; Ogata, Y. Bull. Chem. Soc. J pn. 1981, 54, 793. (b) Katritzky, A. R.; Pilarski, B.; Urogdi, L. Synthesis 1989, 949. 
TABLE 1. Reactions of Aldehydes with Iodine in Ammonia Watera Followed by Treatments with Hydrogen Peroxide, Sodium Azide, or Dicyandiamide, Giving Amides 3, Tetrazoles 4, and Triazines 5

\begin{tabular}{|c|c|c|c|c|}
\hline entry & aldehydes & treatments & conditions & product (yield, \%) \\
\hline 1 & $\mathrm{C}_{6} \mathrm{H}_{5} \mathrm{CHO}(\mathbf{l a})$ & $35 \% \mathrm{H}_{2} \mathrm{O}_{2}$ & r.t., $2.5 \mathrm{~h}$ & amide $\mathbf{3 a}(98)$ \\
\hline 2 & $4-\mathrm{MeOC}_{6} \mathrm{H}_{4} \mathrm{CHO}(\mathbf{l b})$ & $35 \% \mathrm{H}_{2} \mathrm{O}_{2}$ & r.t., $4 \mathrm{~h}$ & amide $\mathbf{3 b}(95)$ \\
\hline 3 & $4-\mathrm{O}_{2} \mathrm{NC}_{6} \mathrm{H}_{4} \mathrm{CHO}(\mathbf{l c})$ & $35 \% \mathrm{H}_{2} \mathrm{O}_{2}$ & r.t., $3 \mathrm{~h}$ & amide $3 c$ (81) \\
\hline 4 & $2-\mathrm{NCC}_{6} \mathrm{H}_{4} \mathrm{CHO}(\mathbf{l d})$ & $35 \% \mathrm{H}_{2} \mathrm{O}_{2}$ & r.t., $2.5 \mathrm{~h}$ & amide $\mathbf{3 d}(93)$ \\
\hline 5 & $4-\mathrm{OHCC}_{6} \mathrm{H}_{4} \mathrm{CHO}(\mathbf{l e})$ & $35 \% \mathrm{H}_{2} \mathrm{O}_{2}$ & r.t., $2.5 \mathrm{~h}$ & amide $3 \mathbf{e}(95)$ \\
\hline 6 & 2-fural dehyde (1f) & $35 \% \mathrm{H}_{2} \mathrm{O}_{2}$ & r.t., $2 \mathrm{~h}$ & amide $3 f(94)$ \\
\hline 7 & thiophene-2-carbal dehyde (1g) & $35 \% \mathrm{H}_{2} \mathrm{O}_{2}$ & r.t., $3.5 \mathrm{~h}$ & amide $\mathbf{3 g}(81)$ \\
\hline 8 & 1-methylpyrrole-2-carbal dehyde (1h) & $35 \% \mathrm{H}_{2} \mathrm{O}_{2}$ & r.t., $2 \mathrm{~h}$ & amide $\mathbf{3 h}$ (93) \\
\hline 9 & $\mathrm{CH}_{3}\left(\mathrm{CH}_{2}\right)_{3} \mathrm{CHO}(\mathbf{l i})$ & $35 \% \mathrm{H}_{2} \mathrm{O}_{2}$ & r.t., $3.5 \mathrm{~h}$ & amide $\mathbf{3 i}(91)$ \\
\hline 10 & $\mathrm{Me}_{3} \mathrm{CCHO}(\mathbf{1 j})$ & $35 \% \mathrm{H}_{2} \mathrm{O}_{2}$ & r.t., $2.5 \mathrm{~h}$ & amide $\mathbf{3 j}(91)$ \\
\hline 11 & $\mathrm{C}_{6} \mathrm{H}_{5} \mathrm{CHO}(\mathbf{l a})$ & $\mathrm{NaN}_{3}, \mathrm{ZnBr}_{2}$ & reflux, $24 \mathrm{~h}$ & tetrazole $\mathbf{4 a}(81)$ \\
\hline 12 & $4-\mathrm{MeOC}_{6} \mathrm{H}_{4} \mathrm{CHO}(\mathbf{l b})$ & $\mathrm{NaN}_{3}, \mathrm{ZnBr}_{2}$ & reflux, $48 \mathrm{~h}$ & tetrazole $\mathbf{4 b}(72)$ \\
\hline 13 & $4-\mathrm{O}_{2} \mathrm{NC}_{6} \mathrm{H}_{4} \mathrm{CHO}(\mathbf{1 c})$ & $\mathrm{NaN}_{3}, \mathrm{ZnBr}_{2}$ & reflux, $17 \mathrm{~h}$ & tetrazole $\mathbf{4 c}(89)$ \\
\hline 14 & 2-furaldehyde (1f) & $\mathrm{NaN}_{3}, \mathrm{ZnBr}_{2}$ & reflux, $24 \mathrm{~h}$ & tetrazole $\mathbf{4 f}(79)$ \\
\hline 15 & thiophene-2-carbaldehyde (1g) & $\mathrm{NaN}_{3}, \mathrm{ZnBr}_{2}$ & reflux, $14 \mathrm{~h}$ & tetrazole $\mathbf{4 g}$ (87) \\
\hline 16 & pyridine-2-carbaldehyde (1k) & $\mathrm{NaN}_{3}, \mathrm{ZnBr}_{2}$ & reflux, $12 \mathrm{~h}$ & tetrazole $\mathbf{4 k}$ (82) \\
\hline 17 & $\mathrm{C}_{6} \mathrm{H}_{5} \mathrm{CH}=\mathrm{CHCHO}$ (1) & $\mathrm{NaN}_{3}, \mathrm{ZnBr}_{2}$ & reflux, $48 \mathrm{~h}$ & tetrazole $4 \mathbf{1}(84)$ \\
\hline 18 & $\mathrm{C}_{6} \mathrm{H}_{5} \mathrm{CHO}(\mathbf{l a})$ & dicyandiamide, $\mathrm{KOH}$ & reflux, $24 \mathrm{~h}$ & triazine $5 \mathbf{a}(78)$ \\
\hline 19 & $4-\mathrm{MeOC}_{6} \mathrm{H}_{4} \mathrm{CHO}(\mathbf{l b})$ & dicyandiamide, $\mathrm{KOH}$ & reflux, $48 \mathrm{~h}$ & triazine $\mathbf{5 b} \mathbf{b}(56)$ \\
\hline 20 & $4-\mathrm{O}_{2} \mathrm{NC}_{6} \mathrm{H}_{4} \mathrm{CHO}(\mathbf{l c})$ & dicyandiamide, $\mathrm{KOH}$ & reflux, $24 \mathrm{~h}$ & triazine $\mathbf{5 c}(\mathbf{7 2})$ \\
\hline 21 & 2-furaldehyde (1f) & dicyandiamide, $\mathrm{KOH}$ & reflux, $24 \mathrm{~h}$ & triazine $\mathbf{5 f}(80)$ \\
\hline 22 & thiophene-2-carbal dehyde ( $\mathbf{l g})$ & dicyandiamide, $\mathrm{KOH}$ & reflux, $24 \mathrm{~h}$ & triazine $\mathbf{5 g}(82)$ \\
\hline 23 & pyridine-2-carbal dehyde (1k) & dicyandiamide, $\mathrm{KOH}$ & reflux, $18 \mathrm{~h}$ & triazine $5 \mathbf{k}(80)$ \\
\hline 24 & $\mathrm{C}_{6} \mathrm{H}_{5} \mathrm{CH}=\mathrm{CHCHO}$ (1) & dicyandiamide, $\mathrm{KOH}$ & reflux, $18 \mathrm{~h}$ & triazine $5 \mathbf{I}(70)$ \\
\hline
\end{tabular}

a A small amount of THF was used as the cosolvent. The aldehydes were allowed to react with iodine in ammonia water at room temperature for $1 \mathrm{~h}$ before the subsequent addition of $\mathrm{H}_{2} \mathrm{O}_{2}, \mathrm{NaN}_{3} / \mathrm{ZnBr}_{2}$, or dicyandiamide/ $\mathrm{KOH}$.

derived by addition of $\mathrm{H}_{2} \mathrm{O}_{2}$ to the transient nitrile product in basic ammonia solution, could be achieved by $\mathrm{I}^{-}$ion.

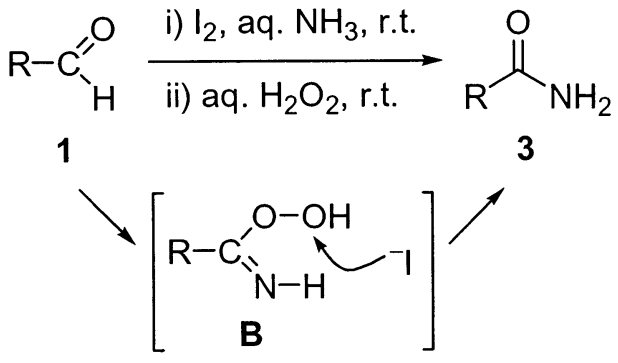

Treatments of 2-cyanobenzal dehyde sequentially with $\mathrm{I}_{2} / \mathrm{aq} \mathrm{NH}_{3}$ and $\mathrm{H}_{2} \mathrm{O}_{2}$ yielded a bisamide $3 \mathbf{d}$ (phthalamide), whereas the similar treatments of terephthaldehyde afforded a bisamide $\mathbf{3 e}$ (terephthamide). Heterocyclic and aliphatic aldehdyes such as 2-fural dehyde, thiophene-2carbaldehyde, 1-methylpyrrole-2-carbaldehyde, valeraldehyde, and pivalaldehyde were also transformed into their corresponding amides $\mathbf{3 f}-\mathbf{j}$ in high yiel ds (81-94\%) by conducting the tandem reactions with $\mathrm{I}_{2} / \mathrm{aq} \mathrm{NH}_{3}$ and $\mathrm{H}_{2} \mathrm{O}_{2}$ in a one-pot procedure.

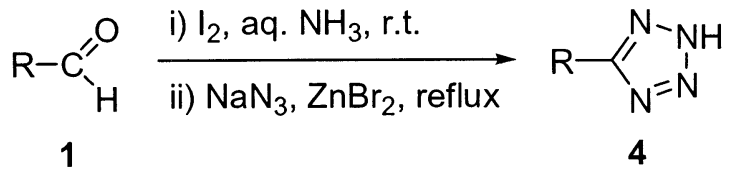

Tetrazoles play important roles in coordination chemistry, as useful ligands, and in medicinal chemistry, as stable isosteres of carboxylic acids. ${ }^{8}$ Tetrazoles can be obtained by addition of azide ion to nitriles. The conventional methods require either drastic reaction conditions or use of unconventional reagents of alkylaluminum, alkylsilicon, and alkyltin azides. ${ }^{9}$ The formation of tetrazoles is accelerated by microwave irradiation of a mixture of $\mathrm{NaN}_{3}$, nitrile, and $\mathrm{NH}_{4} \mathrm{Cl}$ in DMF solution. ${ }^{10}$ In this operation, one should take precautions on the built-up high pressure and the sublimed ammonium azide that may explode in dry form. ${ }^{9 b, d}$ As DMF is not a preferable solvent for industrial use, the reaction in aqueous media is more appealing. ${ }^{1}$ Sharpless and coworkers have recently carried out the addition reactions of nitrile compounds with sodium azide in water by the promotion of zinc salts. ${ }^{11}$ The high heat capacity of water is able to mitigate the explosion hazards on using sodium azide. ${ }^{9 b, d}$ In our study, benzaldehyde was successfully converted to 5-phenyltetrazole (4a) by tandem reactions with $\mathrm{I}_{2} / \mathrm{aq} \mathrm{NH}_{3}$ at room temperature and $\mathrm{NaN}_{3} / \mathrm{ZnBr}_{2}$ at reflux. The optimal conditions applying 1.2 equiv of $\mathrm{NaN}_{3}$ and 1.5 equiv of $\mathrm{ZnBr}_{2}$ afforded an $81 \%$ yield of tetrazole 4a. $\mathrm{ZnI}_{2}$ was an equally efficient promoter, but $\mathrm{ZnCl}_{2}$, $\mathrm{Et}_{3} \mathrm{NHCl}$, or $\mathrm{Al}(\mathrm{OMe})_{3}$ were inferior. By the similar procedures, substituted benzaldehydes (4-methoxybenzaldehyde and 4-nitrobenzal dehyde) and heterocyclic aromatic aldehydes (2-furaldehyde, thiophene-2-carbaldehyde, and pyridine-2-carbaldehyde) also underwent the

(8) (a) Butler, R. N. In Comprehensive Heterocyclic Chemistry; Katritzky, A. R., Rees, C. W., Scriven, E. F. V., Eds.; Pergamon: Oxford, 1966; Vol. 4. (b) Singh, H.; Chawla, A. S.; Kapoor, V. K.; Paul, D.; Malhotra, R. K. Prog. Med. Chem. 1980, 17, 151. (c) Ostrovskii, V A. Pevzner, M. S. Kofmna, T. P. Shcherbinin, M. B. Tselinskii, I. V. Targets Heterocycl. Syst. 1999, 3, 467. (d) Pevzner, M. S. Adv. Heterocycl. Chem. 1999, 75, 1. (e) Zabrocki, J .; Marshall, G. R. Methods Mol. Med. 1999, 23, 417. (f) Zubarev, V. Y.; Ostrovskii, V. A. Chem. Heterocycl. Compd. 2001, 36, 759.

(9) (a) Dunica, J. V.; Pierce, M. E.; Santella, J . B., III. J . Org. Chem 1991, 56, 2395. (b) Huff, B. E.; Staszak, M. A. Tetrahedron Lett. 1993, 34, 8011. (c) Wittenberger, S. J . Org. Prep. Proced. Intl. 1994, 26, 499 (d) Koguro, K.; Oga, T.; Mitsui, S.; Orita, R. Synthesis 1998, 910. (e) Curran, D. P.; Hadida, S.; Kim, S.-Y. Tetrahedron 1999, 55, 8997.

(10) Alterman, M.; Hallberg, A. J. Org. Chem. 2000, 65, 7984.

(11) (a) Demko, Z. P.; Sharpless, K. B. Org. Lett. 2001, 3, 4091. (b) Demko, Z. P.; Sharpless, K. B. J . Org. Chem. 2001, 66, 7945. 
one-pot tandem reactions with I $/ 2 / a q \mathrm{NH}_{3}$ and $\mathrm{NaN}_{3} / \mathrm{ZnBr}_{2}$ to give reasonable yields (72-89\%) of 5-aryltetrazoles (entries 12-16). Cinnamaldehyde was also converted to the corresponding tetrazole $\mathbf{4 1}$ (84\%) with the $\mathrm{C}=\mathrm{C}$ double bond retained.
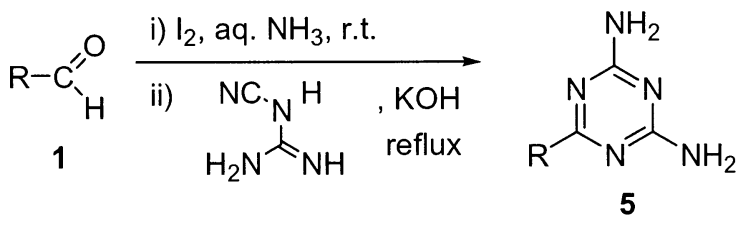

Diamino-1,3,5-triazines are a class of compounds possessing diverse bioactivities such as anti-inflammation, antiallergy, and protective effect against gastric lesions. ${ }^{12}$ Diaminotriazines are al so applicable to material design via assembly of the multiple hydrogen-bonded complexes. ${ }^{13}$ Among a number of synthetic methods for 2,4diaminotriazines, ${ }^{14}$ the most convenient approach utilizes the addition reactions of nitrile compounds with dicyandiamide (also called cyanoguanidine). The reaction is catalyzed by base. In our present study, benzonitrile resulted in situ from the reaction of benzaldehyde with $\mathrm{I}_{2} / \mathrm{aq} \mathrm{NH}_{3}$ was treated with dicyandiamide (1.1 equiv) and $\mathrm{KOH}$ (2.2 equiv) at refluxing temperature for $24 \mathrm{~h}$ to afford 2,6-diamino-4-phenyl-1,3,5-triazine (5a) in 78\% yield. A control reaction of benzonitrile with dicyandiamine (1.1 equiv) and $\mathrm{KOH}$ (2.2 equiv) in aq $\mathrm{NH}_{3} / \mathrm{THF}$ (9:1) yielded $82 \%$ of $\mathbf{5 a}$. Without ammonia, the reaction of benzonitrile (1.1 equiv) and $\mathrm{KOH}$ (2.2 equiv) in aqueous THF at refluxing temperature for $24 \mathrm{~h}$ gave $5 \mathrm{a}$ in $69 \%$ yield. Using a smaller amount of $\mathrm{KOH}$ (1.1 equiv) decreased the yield of $\mathbf{5 a}$ (64\%). Omission of $\mathrm{KOH}$ gave an even lower yield of $\mathbf{5 a}$ (42\%) after refluxing for a prol onged period (48 h). It appeared that our current onepot tandem reaction in ammonia water was the method of choice for the direct conversion of al dehyde to triazines. Thus, a series of 2,4-diaminotriazines were synthesized by the one-pot tandem reactions using appropriate aldehydes as the starting materials (entries 18-24).

In summary, we have explored a new methodology using one-pot tandem reactions for the di rect conversion of aldehydes to amides, tetrazoles, and triazines, via addition of $\mathrm{H}_{2} \mathrm{O}_{2}, \mathrm{NaN}_{3} / \mathrm{ZnBr}_{2}$, and dicyandiamide/ $\mathrm{KOH}$ to the intermediate nitriles. These reactions are conducted smoothly in aqueous media, and the desired products are obtained simply by extraction or filtration.

(12) (a) Hasegawa, Y.; Yanagisawa, T.; Okui, Y.; Sato, T.; Hosaka K.; Chin, M.; Mitsuhashi, H. Chem. Pharm. Bull. 1991, 39, 3180. (b) Brzozowski, Z.; Saczewski, F.; Gdaniec, M. Eur. J . Med. Chem. 2000, 35, 1053. (c) J ensen, N. P.; Ager, A. L.; Bliss, R. A.; Canfield, C. J . Kotecka, B. M.; Rieckmann, K. H.; Terpinski, J .; J acobus, D. P. J . Med. Chem. 2001, 44, 3925.

(13) (a) Beijer, F. H.; Sijbesma, R. P.; Vekemans, J . A. J . M.; Meijer, E. W.; Kooijman, H.; Spek, A. L. J . Örg. Chem. 1996, 61, 6371. (b) Deans, R.; Rotello, V. M. J . Org. Chem. 1997, 62, 4528. (c) Balogh, D. T.; Dhanabalan, A.; Dynarowicz-Latka, P.; Schenning, A. P. H. J ; Oliveira, O. N., J r.; Meijer, E. W.; J anssen, R. A. J . Langmuir 2001 17, 3281. (d) Frankamp, B. L.; Uzun, O.; Il han, F.; Boal, A. K.; Rotello, V. M. J . Am. Chem. Soc. 2002, 124, 892.

(14) (a) Smolin, E. M.; Rapoport, I. In The Chemistry of Heterocyclic Compounds; Weissberg, A., Ed.; Wiley: New York, 1959; Vol. 13, s-Triazines. (b) Quirke, J. M. E. In Comprehensive Heterocyclic Chemistry; Katritzky, A. R., Rees, C. W., Boulton, A. J ., McKillop, A., Eds.; Pergamon: Oxford, 1984; Vol. 3, Chapter 2.20, 1,3,5-Triazines. (c) Cooke, G.; Augier de Cremiers, H.; Rotello, V. M.; Tarbit, B.; Vanderstraeten, P. E. Tetrahedron 2001, 57, 2787.
The advantageous features of this method, including simple operation, high yielding, and solvent reuse, provide an excellent opportunity for parallel synthesis and industrial production. This method can also circumvent the problem in prior preparation of nitrile compounds from halides and toxic cyanides.

\section{Experimental Section}

CAUTION: It is known that iodine reacts with ammonia water under certain conditions to give a black powder of nitrogen triiodide monoamine $\left(\mathrm{NI}_{3} \cdot \mathrm{NH}_{3}\right) .15$ The dry powder explodes readily by mechanical shock, heat, or irradiation. Although we did not have any incidents when handling the reactants in this study, one should avoid using excess reagent.

Representative Procedure for Transformation of Aldehydes into Amides. A solution of appropriate al dehyde (1) $-\mathbf{j}$, $5 \mathrm{mmol}$ ) and iodine $(5.5 \mathrm{mmol}$ ) in ammonia water $(30 \mathrm{~mL}$ of $28 \%$ solution) and THF (5 mL) was stirred at room temperature for $1 \mathrm{~h}$. The dark solution became colorless at the end of reaction. Aqueous $\mathrm{H}_{2} \mathrm{O}_{2}$ ( $3 \mathrm{~mL}$ of $35 \%$ solution) was then added dropwise. The reaction mixture was stirred for $2-4 \mathrm{~h}$ and extracted with $\mathrm{CH}_{2} \mathrm{Cl}_{2}$. The organic phase was washed with brine, dried $\left(\mathrm{Na}_{2}-\right.$ $\mathrm{SO}_{4}$ ), and concentrated in vacuo. The residue was rinsed with hexane/EtOAc (1:3) to give a pure amide product (3a-j, 81$98 \%$ yields). Amides $\mathbf{3} \mathbf{a}-\mathbf{j}$ are characterized by their physical and spectral properties that are consistent with known compounds (see Supporting I nformation).

Representative Procedure for Transformation of Aldehydes into Tetrazoles. CAUTION: Although a study has shown this protocol only rel eases a minute amount of hydrazoic acid $\left(\mathrm{HN}_{3}\right)$, 11 one should still avoid using excess amounts or high concentrations of sodium azide in the following procedure.

A solution of appropriate aldehyde $(1 \mathrm{mmol})$ and iodine (1.1 $\mathrm{mmol}$ ) in ammonia water ( $9 \mathrm{~mL}$ of $28 \%$ solution) and THF (1 $\mathrm{mL}$ ) was stirred at room temperature for $1 \mathrm{~h}$. The dark solution became colorless at the end of reaction. A mixture of $\mathrm{NaN}_{3}(1.2$ $\mathrm{mmol})$ and $\mathrm{ZnBr}_{2}(1.5 \mathrm{mmol})$ was then added. The reaction mixture was heated at reflux for $12-48 \mathrm{~h}$ with vigorous stirring. $\mathrm{HCl}(10 \mathrm{~mL}$ of $1 \mathrm{M}$ solution) and EtOAc $(50 \mathrm{~mL})$ were added, and vigorous stirring was continued until no solid was present and the aqueous layer had a $\mathrm{pH}$ of 1 . The organic phase was concentrated in vacuo, and the remaining solids were rinsed with EtOAc $(20 \mathrm{~mL})$ to give a pure tetrazole product $(\mathbf{4 a}-\mathbf{c}, \mathbf{f}, \mathbf{g}, \mathbf{k}, \mathbf{I}$, $72-89 \%$ yiel ds). These 5 -substituted tetrazoles are characterized by their physical and spectral properties that are consistent with known compounds (see Supporting I nformation).

Representative Procedure for Transformation of Aldehydes into Triazines. A solution of appropriate aldehyde (1 $\mathrm{mmol}$ ) and iodine ( $1.1 \mathrm{mmol})$ in ammonia water $(9 \mathrm{~mL}$ of $28 \%$ solution) and THF ( $1 \mathrm{~mL}$ ) was stirred at room temperature for $1 \mathrm{~h}$. The dark solution became colorless at the end of the reaction. A mixture of dicyandiamide $(1.1 \mathrm{mmol})$ and $\mathrm{KOH}(2.2 \mathrm{mmol})$ was then added. The reaction mixture was heated at reflux for $12-48 \mathrm{~h}$. The suspended solid products were filtered and rinsed with $\mathrm{Et}_{2} \mathrm{O}$ to give a pure diaminotriazine $(\mathbf{5 a}-\mathbf{c}, \mathbf{f}, \mathbf{g}, \mathbf{k}, \mathbf{I}, 56-$ $82 \%$ yields). These 6-substituted 2,4-diamino-1,3,5-triazines are characterized by their physical and spectral properties that are consistent with known compounds (see Supporting Information).

Acknowledgment. We thank the National Science Council for financial support.

Supporting Information Available: Physical and spectral data and pertinent references for amides 3, tetrazoles 4 , and triazines $\mathbf{5}$. These materials are available free of charge via the Internet at http://pubs.acs.org.

\section{J $0026407 Z$}

(15) (a) Southwick, P. L.; Christman, D. R. J . Am. Chem. Soc. 1952 74, 1886. (b) Roesky, H. W.; Möckel, K. In Chemical Curiosities; VCH: Weinheim, Germany 1996; pp 292-293. 